\title{
Interspecific competition between Enteromorpha (Ulvales: Chlorophyceae) and Fucus (Fucales: Phaeophyceae) germlings: effects of nutrient concentration, temperature, and settlement density
}

\author{
Henning Steen*
}

Department of Biology, Section for Marine Biology and Limnology, University of Oslo, PO Box 1069 Blindern, 0316 Oslo, Norway

\begin{abstract}
The increased abundance of ephemeral algae and corresponding decline in perennial fucoids observed in eutrophic (nutrient-rich) waters could be caused by eutrophication-driven shifts in the competitive relationship between the 2 groups as early as the germling stage. During the initial post-settlement period germlings are exposed to large temporal variations in temperature, which may influence their performance and competitive interactions. Effects of temperature, nutrient concentration, and settlement density on the competitive relationship between germlings of Fucus serratus L. and F. evanescens C. Agardh and of the ephemeral alga Enteromorpha compressa (Linnaeus) Greville were examined using factorially designed culture experiments. In monocultures, germling growth of both Fucus species and E. compressa was generally stimulated by nutrient enrichment (32 $\mu \mathrm{mol}$ nitrate/ammonia and $2 \mu \mathrm{mol}$ phosphate $\mathrm{l}^{-1}$ seawater) and high temperature $\left(17^{\circ} \mathrm{C}\right.$ compared to $7^{\circ} \mathrm{C}$ ), and negatively related to settlement density (10 to 50 germlings $\mathrm{cm}^{-2}$ for Fucus, 30 to 130 germlings $\mathrm{cm}^{-2}$ for E. compressa). In mixed cultures, interspecific competition effects of E. compressa on F. serratus and $F$. evanescens germlings increased with increasing nutrient and temperature levels. In the nutrient-enriched cultures, interspecific competition from E. compressa suppressed the yield of Fucus spp. by 80 to $100 \%$ at $17^{\circ} \mathrm{C}$, with $F$. evanescens being more suppressed than F. serratus, whereas the suppressive effects of E. Compressa on Fucus germlings were $<60 \%$ at $7^{\circ} \mathrm{C}$. These results suggest that competition from ephemeral algae at early life stages may be a reason for the decline of fucoids in eutrophic waters and that reproduction at low temperatures, as in species like F. serratus and F. evanescens, may shield the vulnerable initial germling stages from the severest competition pressure by ephemeral algae.
\end{abstract}

KEY WORDS: Fucus spp. · Enteromorpha compressa · Germlings · Competition · Nutrients · Temperature Resale or republication not permitted without written consent of the publisher

\section{INTRODUCTION}

The most widely noted floristic changes associated with eutrophication (i.e. nutrient enrichment) of coastal waters are the increased abundance of ephemeral algae and the corresponding decline or disappearance of large perennial algae such as fucoids (Fletcher 1996 and references therein). Interpretations of this phenomenon are largely based on descriptive data, water chemistry, and measurements of selected physiological traits, while the underlying mechanisms have been less explored. The observed changes in vegetation are readily attributed to eutrophication-driven shifts in competitive relationships between these algae groups, although effects of nutrient enrichment on species interactions in seaweeds have rarely been subjected to experimental testing (Choi 2001, Worm et al. 2001). A common explanation for the observed patterns is that, if they are not directly harmed by eutrophication, perennials such as fucoids are unsuccessful in competition with more nutrient-facilitated ephemeral algae (Duarte 1995, Pedersen \& Borum 1996, 1997). Large benthic macroalgae support a wide variety of associated organisms and their decline will inevitably reduce habitat and species diversity. 
Along Atlantic European coasts, Fucus serratus L. is the dominant seaweed on lower rocky shores. Another low-shore fucoid, F. evanescens C. Agardh, was introduced to southern Scandinavia in the 1890s (Simmons 1898) and rarely forms associations, with the exception of some eutrophic fjord systems, e.g. the inner Oslofjord, where its abundance has decreased following improved sewage treatment (Bokn et al. 1992). The abundance of $F$. evanescens thus appears to be positively associated with eutrophication, whereas that of most other fucoids (including F. serratus) appears to be negatively related to eutrophication. Although the exact mechanisms behind the apparent nutrient-induced changes in the abundance of F. serratus and F. evanescens remain unknown, interspecific differences in autecology and competitive ability of the early post-settlement stages may contribute. F. serratus and F. evanescens reproduce at lower water temperatures than most other north European fucoids (Steen \& Rueness 2004), and this has been proposed as a potential mechanism that may protect the most vulnerable initial germling stages from the severest competition pressure by ephemeral algae, whose growth is reduced at low temperatures (Lotze et al. 1999, Lotze \& Worm 2002). This hypothesis relies on the assumption that competition effects of ephemeral algae on fucoid germlings are positively related to temperature, which has so far not been tested.

Competition arises when shared resources are limited, and is commonly detected by manipulating the density of competitors and examining the effects on growth and survival (Begon et al. 1986). Considering the diversity of designs developed for studying interspecific competition in terrestrial plants and their extensive usage (Schoener 1983, Snaydon 1991), such experimental designs have only occasionally been applied in studies of interspecific competition in seaweeds (Russell \& Fielding 1974, Enright 1979, Karez \& Chapman 1998, Choi 2001). Although there are some obvious differences, terrestrial plants and seaweeds share several features such as remaining fixed to the substrate and competing for similar resources (e.g. light, nutrients and space), so the same principles of competition should apply and experimental approaches be interchangeable between these groups of organisms. The 2 classical experimental approaches for studying interspecific competition in binary plant mixtures are replacement (or substitutive) and additive designs. In standard replacement designs, the performance of 2 competing species in mixed stands is compared to their performance in pure stands (de Wit 1960). In this design the mixtures are formed by serially replacing a given number of plants of one species by the same number of plants of the second species while the overall density is held constant. One major disadvantage of the replacement design is that the effects of intra- and interspecific competition are confounded, as the density of one species is reduced while that of the other is simultaneously increased (Connolly 1986, Cousens 1996). In the additive design, the density of one species is held constant while plants of the competitor species are added (Donald 1958). As a consequence, overall plant density is always greater in mixtures than in pure stands, which confounds the effects of overall density with those of proportional density of the components (Firbank \& Watkinson 1985, 1990). The shortcomings of the replacement and additive designs can be avoided by using more elaborate response-surface or bivariate factorial designs, where the density of both species is varied independently (Law \& Watkinson 1987, Snaydon 1991).

Although it is more or less accepted that physical and biological factors interactively affect marine community dynamics (Carpenter 1990), there have been few experimental studies evaluating the combined effects of multiple environmental factors on species interactions at the germling stage in fucoid seaweeds (Choi 2001, Worm et al. 2001). The objective of the present study was to examine interactive effects of nutrient concentration, temperature and settlement density on the competitive relationship between germlings of the fucoids Fucus serratus and $F$. evanescens and of the ephemeral alga Enteromorpha compressa (Linnaeus) Greville in laboratory cultures, using bivariate factorial competition experiments. The manipulated factors were arranged in a fully crossed orthogonal factorial design, which made it possible to estimate their effects and interactions on the early life stages in each of these species and enabled cross-species comparison of responses.

\section{MATERIALS AND METHODS}

Experimental design. I collected fucoid plants from intertidal rocks near Dröbak (59 $40^{\prime} \mathrm{N}, 10^{\circ} 38^{\prime} \mathrm{E}$ ) in the Oslofjord, Norway, on 1 March 1999 (Fucus serratus) and 28 May 1999 (F. evanescens). In the laboratory, receptacles were excised and repeatedly washed in cold tap water to remove epiphytes, then wrapped in moist paper and stored overnight in a refrigerator. The following day, zygote suspensions were obtained using standard techniques for fucoids (Quatrano 1980). Zygotes of Enteromorpha compressa (collected in Dröbak and maintained as stock culture at the University of Oslo) were obtained by cutting gametophytic thalli into small fragments (5 to $10 \mathrm{~mm}^{2}$ ) and incubating the fragments in polystyrene Petri dishes containing IMR 1/2 medium (Eppley et al. 1967). Dishes were cultivated under a 16:8 h light $\left(\sim 50 \mu \mathrm{mol}\right.$ photons $\left.\mathrm{m}^{-2} \mathrm{~s}^{-1}\right)$ : dark cycle at $17^{\circ} \mathrm{C}$ to allow gamete liberation. To remove gametophytic material, E. compressa solutions were passed through a $45 \mu \mathrm{m}$ filter $2 \mathrm{~d}$ after incubation and the filtrate was kept. The initial concentration of 
zygotes was estimated using a Palmer-Maloney chamber under a stereomicroscope. By diluting the original zygote suspensions, 2 sub-suspensions varying 4-fold in zygote concentration were made for each species. A fixed volume of each species sub-suspension was seeded into plastic chambers, each with 35 quadratic plexiglass slides $\left(9 \mathrm{~cm}^{2}\right)$ on the floor. Mixed cultures of Fucus spp. and E. compressa were obtained by seeding zygote suspensions of both species into to the same chambers.

All chambers were incubated at $12^{\circ} \mathrm{C}$ to allow settlement. After 1 wk incubation, the number of settlers in 4 subsections of each slide was counted under a stereomicroscope. The standardised Morisita index (Tsuji \& Tsuji 1998) was used as a quantitative measure of the distribution of individuals per species per slide. The index ranges from -1 to 1 , and separates regular ( -1 to $-0.5)$, random ( -0.5 to 0.5$)$, and contagious/clumped $(0.5$ to 1) patterns of distribution. Based on criteria such as closeness to desired density levels and non-contagious distribution of settlers, 16 slides were chosen from each density combination and placed in separate growth chambers $\left(100 \mathrm{~cm}^{3}\right)$. Evenly distributed monocultures and mixtures were used to avoid the confounding effects of spatial distribution on competition.

The bivariate factorial arrangement of mono- and mixed species density combinations made it possible to test interactive effects of target species density (2 levels: low and high) and competitor species density (3 levels: zero, low, and high) in both directions simultaneously, with either Fucus spp. or Enteromorpha compressa as the target species (Fig. 1). The bivariate factorial competition experiment (8 density combinations) was run at 2 temperatures $\left(7\right.$ and $17^{\circ} \mathrm{C}$, covering most of the temperature range in the species' reproduction seasons) and 2 nutrient concentrations (seawater and nutrient-enriched seawater: see below) using a crossed orthogonal factorial arrangement. This design was used in both experiments ( $F$. serratus versus $E$.

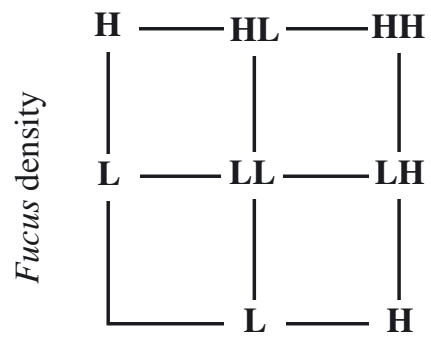

Enteromorpha density

Fig. 1. Matrix showing bivariate factorial designed competition experiments, in which densities (L: low, H: high) of the 2 components (Fucus spp. and Enteromorpha compressa) are varied independently compressa and F. evanescens versus E. compressa). I used 4 replicate slides for each treatment combination (32) in both experiments, giving a total of 256 slides.

The high nutrient level was obtained by enriching autoclaved seawater with $32 \mu \mathrm{M} \mathrm{N}$ (nitrate and ammonia added at a ratio of 1:1) and $\sim 2.0 \mu \mathrm{M} P$ (phosphate), which is similar to nutrient concentrations recorded in eutrophic areas (Kristiansen \& Paasche 1982). Culture medium was changed thrice a week (except for the first week during which it was left unchanged), and cultivated under a 16:8 h light:dark cycle, at $50 \mu \mathrm{mol}$ photons $\mathrm{m}^{-2} \mathrm{~s}^{-1}$. Prior to each renewal of growth medium, the slides were carefully sprayed with seawater to remove necromass and dross. To reduce growth of diatoms and prokaryotes, germanium dioxide $\left(0.2 \mathrm{mg} \mathrm{l}^{-1}\right.$, a concentration recommended by Markham \& Hagmeier 1982) and penicillin (2 $\left.\mathrm{mg} \mathrm{l}^{-1}\right)$ were added to the cultures.

Measurements and response variables. After $1 \mathrm{mo}$ of cultivation under experimental conditions, all slides were sampled. For each species the number of germlings in 4 subsections (with areas ranging from 0.25 to $1 \mathrm{~cm}^{2}$, depending on germling density) per slide was counted, and survivorship estimated as the proportional difference between the numbers of germlings at the end and start of the experiments. Additionally, the sizes of the parenchymatous portion (excluding rhizoids) of 10 haphazardly selected individuals per species per slide were measured. In the case of Enteromorpha compressa, the length of germlings was measured using a ruler, or if germlings were $<1 \mathrm{~cm}$ long, using an eyepiece-measuring device through a stereomicroscope. In the case of Fucus spp., surface area projections of germlings (henceforth referred to as germling area) were measured by forcing individuals down onto a plane with a microscope slide and taking their photographs using a video camera through a stereomicroscope (Steen 2003b). The photographs were digitised and germling areas estimated using a software tool (Scion Image, available from Scion Corporation: www.scioncorp.com). To keep edge-effects at a minimum and equal for all slides, the positions of individuals and subsections to be sampled were kept as similar as possible, and always $>3 \mathrm{~mm}$ away from the edge. In order to estimate total yield per species per slide at the end of the experiments, algae material was shaved off the slides, briefly soaked in freshwater to remove salt, dried at $50^{\circ} \mathrm{C}$ and weighed.

Competition can be measured using indices that compare the yield of plants in the presence and absence of neighbours. In 2-species mixtures, plants may compete both with conspecifics (intraspecific competition) and with contraspecifics (interspecific competition), and yield suppression can be due to a multitude of possible levels of intra- and interspecific 
competition. By varying the density of both species independently, as in the present experiments, it is possible to separate the effects of intra- and interspecific competition. Because plant yield in the absence of competitors often depends on environmental conditions, it is more meaningful to assess effects of competitive interactions on a relative rather than an absolute basis (Grace 1995). The relative effect of intraspecific competition $\left(R_{\text {Intra }}\right)$ in high-density monocultures was estimated as the difference between the observed yield $\left(Y_{\text {mon }}\right)$ and the potential 'competition-free' yield $\left(Y_{\text {pot }}\right.$ ) that would have been produced by the same number of plants in the absence of competition, relative to $\mathrm{Y}_{\text {pot }}$.

$$
R_{\text {Intra }}=\left(Y_{\text {mon }}-Y_{\text {pot }}\right) \times Y_{\text {pot }}^{-1} \times 100
$$

The potential 'competition-free' yield ( $\left.Y_{\text {pot }}\right)$ of a species was obtained by projecting the biomass produced in a culture with density-independent growth and mortality (approximately the low-density monocultures in the present experiments) onto higher densities (Jolliffe et al. 1984). The relative effect of interspecific competition $\left(R_{\text {Inter }}\right)$ was estimated from the difference between the yield of a species in monoculture ( $\left.Y_{\text {mon }}\right)$ and mixture $\left(Y_{\text {mix }}\right)$, relative to $Y_{\text {mon, }}$ at a given plant density.

$$
R_{\text {Inter }}=\left(Y_{\text {mix }}-Y_{\text {mon }}\right) \times Y_{\text {mon }}{ }^{-1} \times 100
$$

These competition indices measures the relative reduction in the yield of a species due to intraspecific $\left(R_{\text {Intra }}\right)$ and interspecific $\left(R_{\text {Inter }}\right)$ competition on a scale from 0 (no competition) to $-100 \%$ (competitive exclusion). Positive values indicate density facilitation.

Statistical analyses. Data were analysed by univariate 4 -way analyses of variance (ANOVA) to test for treatment effects on germling survival and size. The independent variables temperature, nutrient concentration, target-species density, and competitor species density were considered orthogonal and fixed. The magnitude of treatment effects was estimated as the percentage of variance explained using the omegasquared $\left(\omega^{2}\right)$ measure as recommended for fixed-factor models (Howell 1992). The direction of treatment effects and interactions was interpreted graphically. Lower-order ANOVAs were performed to test for effects within subgroups of treatments, and Student $t$-tests were used for post hoc comparisons of treatment pairs without applying multiple testing adjustments (e.g. Bonferroni adjustments) of significance levels (Hurlbert \& Lombardi 2003, Moran 2003).

Probability levels ( $p$-values) were estimated by resampling (without replacement) and randomly redistributing the data over treatment levels and, for each run, recalculating the test statistic ( $F$-ratio in the case of ANOVA, $t$-value in the case of $t$-tests), as described in Crowley (1992). The p-value is given by the number of times the resampled test statistic proves to be at least as extreme as the original test statistic divided by the total number of resamplings (1000). Compared to conventional parametric procedures, which are based on the assumption that data are normally distributed, resampling techniques are independent of data distribution and are considered to give more reliable statistical estimates, especially in cases of low $\mathrm{N}$ where the shape of the underlying distributions cannot be determined (Crowley 1992). To ensure homogeneity of variances, as required by resampling methods involving randomisation of data across treatments, germling area data were logarithmically transformed, and survival ratios and competition indices were angular (arcsine-square-root)transformed. Confidence intervals were constructed using the bootstrap percentile method (Dixon 2001). By this method, the 2.5 and 97.5 percentiles of the bootstrapped distribution (resampled with replacement within each level of variation) are used as the limits of a $95 \%$ confidence interval, which correspond to the 25th and 975th largest values when 1000 resamplings are run. For the germling size measurements, where there were variation components both within and between slides, multistage resamplings were performed with the lower level (slide) nested at the higher level (treatment). All computations were done in Microsoft Excel for Windows, and the resamplings were run using an Excel macro, available from Resampling Stats (www.resample.com).

\section{RESULTS}

\section{Method and treatment efficacy}

The standardised Morisita index ranged between -0.5 and 0.2 , indicating that germlings of each species were randomly distributed on all slides in both experiments. As a result of the dilution procedure, the density of settled germlings fell into 2 significantly distinct categories for each species in both experiments ( $t$-tests, p always $<0.001)$. Mean $( \pm 95 \%$ confidence limits $)$ settlement densities were: $10.7 \pm 0.2$ and $40.8 \pm 0.9$ germlings $\mathrm{cm}^{-2}$ for Fucus serratus, $11.7 \pm 0.4$ and $49.3 \pm$ 1.1 germlings $\mathrm{cm}^{-2}$ for $F$. evanescens, and $31.7 \pm 0.9$ and $124 \pm 2.9$ germlings $\mathrm{cm}^{-2}$ for Enteromorpha compressa. The reason for using a higher density range for E. Compressa than for Fucus spp. is that E. Compressa commonly recruits at higher densities than Fucus spp., and the densities applied were probably realistic given the natural settlement variations of these algae (Creed et al. 1996, Lotze 1998). There were no significant differences in intraspecific density between levels of subsequent treatments (competitor species density, tem- 
perature and nutrient concentration) for any of the species in either experiment (3-way ANOVAs, $p$ always $>0.05)$. Comparison of the 2 experiments revealed that germling settlement density was higher (9 to $17 \%$ ) in cultures of $F$. evanescens than $F$. serratus, while the settlement density of E. compressa germlings was higher (11 to $14 \%$ ) in the $F$. serratus experiment than in the $F$. evanescens experiment. Compared to the large differences between density categories within each species (300 to $400 \%$ ), the differences in settlement density categories between the 2 experiments were assumed to have negligible effects on responses, and were ignored whenever treatment effects were compared between the 2 experiments.

\section{Survival}

The 4-way ANOVA (Table 1) showed significant 3-way interaction effects of main factors $(\mathrm{T} \times \mathrm{N} \times \mathrm{C}$ and $\mathrm{T} \times \mathrm{I} \times \mathrm{C}$ ) on germling survival in Fucus serratus and F. evanescens (Table 1). The strongest 3-way interaction was that of $\mathrm{T} \times \mathrm{N} \times \mathrm{C}$, which explained 4 and $8 \%$ of the variation in survival of $F$. serratus and $F$. evanescens germlings, respectively. In monocultures, survival rates of germlings of both Fucus species were in the range of 60 to $85 \%$ (Fig. 2). The presence of Enteromorpha compressa had a negative effect on Fucus spp. germling survival in the nutrient-enriched cultures at $17^{\circ} \mathrm{C}$, but had little effect at the other nutri- ent and temperature combinations (Fig. 2). The negative effect of $E$. compressa on germling survival in the nutrient-enriched cultures at $17^{\circ} \mathrm{C}$ was less pronounced in F. serratus than in F. evanescens. Most of the latter species' germlings were killed by competition from $E$. compressa in the nutrient-enriched mixtures at $17^{\circ} \mathrm{C}$ (Fig. 2).

To test for differences in responses of Enteromorpha compressa germlings between the 2 experiments (Fucus serratus versus E. compressa and F. evanescens versus E. compressa) this was incorporated into the ANOVAs as a 5th factor. The responses (survival, length and biomass) of E. compressa germlings did not differ significantly between the 2 experiments (5-way ANOVAs, $p>0.05$ for all main and interaction terms involving the 5th factor), and the 2 data groups were pooled post hoc (Table 1 and Figs. 2 to 5). The 4 -way ANOVA showed significant effect of nutrient enrichment and significant interaction effects of temperature and intraspecific density $(\mathrm{T} \times \mathrm{I})$ on the survival of $E$. compressa germlings (Table 1). The presence of Fucus spp. (C) had no effect on the survival of E. compressa for any temperature, nutrient or density combinations (Table 1). Survival of E. compressa was generally in the range of 30 to $50 \%$, and was lower than that of Fucus spp. germlings in monocultures (Fig. 2). E. compressa survival decreased with increasing temperature, nutrient concentration and intraspecific density, and was lowest in the nutrient-enriched high-density cultures at $17^{\circ} \mathrm{C}$ (Fig. 2).

Table 1. Fucus serratus (F. ser.), F. evanescens (F. eva.) and Enteromorpha compressa (E. com.). Results of 4-way analysis of variance (ANOVA) of treatment effects on survival and size in germlings after 1 mo treatment. Magnitudes of explained variance $\left(\omega^{2}\right)$ for significant treatment effects $(\mathrm{p}<0.05)$ and residuals are given as percentages. Size was recorded as area for Fucus spp., and as length for E. compressa. Data for E. compressa was pooled from 2 experiments (F. serratus vs E. compressa and F. evanescens vs E. compressa). Residual df $=72$ (F. serratus, F. evanescens), 168 (E. compressa). Residual MS $=0.008$ (F. serratus survival), 0.008 (F. evanescens survival), 0.003 (E. compressa survival), 0.001 (F. serratus size), 0.003 (F. evanescens size), 0.002 (E. compressa size)

\begin{tabular}{|c|c|c|c|c|c|c|c|c|c|c|c|c|c|}
\hline \multirow{3}{*}{ Source of variation } & \multirow{3}{*}{$\mathrm{df}$} & \multicolumn{6}{|c|}{ - Survival } & \multirow{2}{*}{\multicolumn{2}{|c|}{ Fser }} & \multicolumn{2}{|c|}{ - Size } & \\
\hline & & \multicolumn{2}{|c|}{ F. ser. } & \multicolumn{2}{|c|}{ F eva. } & \multicolumn{2}{|c|}{ E. Com. } & & & \multicolumn{2}{|c|}{ F eva. } & \multicolumn{2}{|c|}{ E. com. } \\
\hline & & $F$ & $\omega^{2}$ & $F$ & $\omega^{2}$ & $F$ & $\omega^{2}$ & $F$ & $\omega^{2}$ & $F$ & $\omega^{2}$ & $F$ & $\omega^{2}$ \\
\hline Temperature $(\mathrm{T})$ & 1 & 59.7 & $(12)$ & 347 & $(20)$ & 222 & $(46)$ & 286 & (10) & 1174 & (18) & 5024 & $(60)$ \\
\hline Nutrients (N) & 1 & 98.1 & (20) & 310 & (18) & 18.7 & (4) & 113 & (4) & 781 & (12) & 1131 & (13) \\
\hline Intraspecific density (I) & 1 & 23.5 & (5) & 18.7 & (1) & 37.1 & (8) & 1068 & $(37)$ & 452 & (7) & 1413 & (17) \\
\hline Competitor density (C) & 2 & 26.6 & (11) & 103 & (12) & 1.32 & & 300 & (21) & 522 & (16) & 0.33 & \\
\hline $\mathrm{T} \times \mathrm{N}$ & 1 & 49.5 & (10) & 348 & (20) & 3.05 & & 115 & (4) & 883 & (14) & 560 & $(7)$ \\
\hline $\mathrm{T} \times \mathrm{I}$ & 1 & 2.57 & & 1.25 & & 12.0 & $(2)$ & 9.04 & $(<1)$ & 3.66 & & 98.8 & (1) \\
\hline $\mathrm{N} \times \mathrm{I}$ & 1 & 2.28 & & 0.57 & & 1.60 & & 5.76 & $(<1)$ & 18.1 & $(<1)$ & 0.04 & \\
\hline $\mathrm{T} \times \mathrm{C}$ & 2 & 17.9 & $(7)$ & 79.7 & (9) & 0.31 & & 126 & (9) & 397 & (12) & 0.42 & \\
\hline $\mathrm{N} \times \mathrm{C}$ & 2 & 21.6 & (9) & 71.3 & (8) & 0.65 & & 94.5 & (7) & 338 & (10) & 1.22 & \\
\hline $\mathrm{I} \times \mathrm{C}$ & 2 & 1.25 & & 0.74 & & 0.74 & & 2.04 & & 7.35 & $(<1)$ & 0.33 & \\
\hline $\mathrm{T} \times \mathrm{N} \times \mathrm{I}$ & 1 & 0.01 & & 0.84 & & 2.02 & & 6.02 & $(<1)$ & 16.9 & $(<1)$ & 0.84 & \\
\hline $\mathrm{T} \times \mathrm{N} \times \mathrm{C}$ & 2 & 10.9 & (4) & 67.0 & (8) & 0.44 & & 50.4 & (3) & 261 & (8) & 0.04 & \\
\hline $\mathrm{T} \times \mathrm{I} \times \mathrm{C}$ & 2 & 3.05 & (1) & 3.70 & $(<1)$ & 0.94 & & 4.53 & $(<1)$ & 11.9 & $(<1)$ & 0.62 & \\
\hline $\mathrm{N} \times \mathrm{I} \times \mathrm{C}$ & 2 & 1.98 & & 1.86 & & 0.38 & & 7.55 & $(<1)$ & 0.04 & & 0.45 & \\
\hline $\mathrm{T} \times \mathrm{N} \times \mathrm{I} \times \mathrm{C}$ & 2 & 0.21 & & 2.52 & & 0.26 & & 1.20 & & 3.06 & & 1.44 & \\
\hline Residual & & & $(20)$ & & (5) & & $(40)$ & & (3) & & (1) & & (2) \\
\hline
\end{tabular}



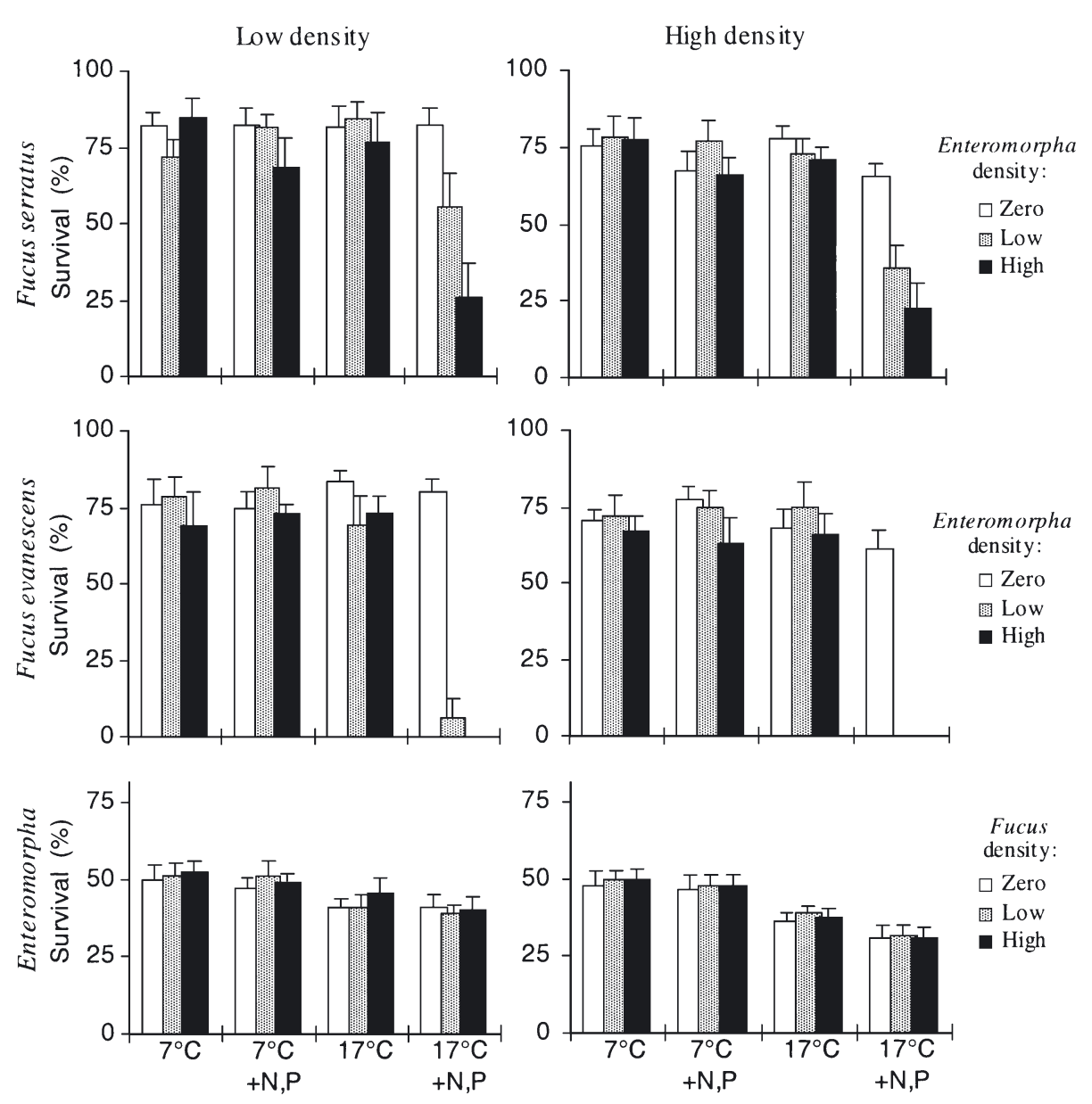

Fig. 2. Fucus serratus, F. evanescens and Enteromorpha compressa. Mean survival of germlings at low and high settlement densities in monocultures and mixtures after 1 mo treatment at 7 and $17^{\circ} \mathrm{C}$, in seawater and $\mathrm{N}+$ P-enriched seawater. For E. compressa, data of 2 experiments was pooled ( $F$. serratus vs E. compressa and $F$. evanescens vs $E$. compressa). Error bars: upper $95 \%$ confidence limits

\section{Germling size}

There were significant 3-way interaction effects of main factors $(\mathrm{T} \times \mathrm{N} \times \mathrm{I}, \mathrm{T} \times \mathrm{N} \times \mathrm{C}$ and $\mathrm{T} \times \mathrm{I} \times \mathrm{C})$ on germling area in both Fucus species, and a significant 3 -way interaction of $\mathrm{N} \times \mathrm{I} \times \mathrm{C}$ on germling area in $F$. serratus (Table 1). The strongest 3-way interaction was that of $\mathrm{T} \times \mathrm{N} \times \mathrm{C}$, which explained 3 and $8 \%$ of the variation in germling area in $F$. serratus and $F$. evanescens, respectively. In monocultures, the germling area of both Fucus species generally increased with increasing temperature and nutrient level and decreased with increasing intraspecific density (Fig. 3). The effect of nutrient concentration on Fucus spp. germling area increased with increasing settlement density, and in the low-density monocultures nutrient enrichment increased the germling area significantly more in $F$. evanescens than in $F$. serratus at both temperatures tested (Fig. 3, $t$-tests, p always < 0.05). Fucus spp. germling area decreased with increasing density of $E$. compressa; and this effect increased with increasing temperature and nutrient level, and depended on Fucus spp. germling density and species (Fig. 3).
The 4-way ANOVA (Table 1) showed that the effect of temperature on the length of Enteromorpha compressa germlings depended on nutrient concentration and intraspecific density (significant $\mathrm{T} \times \mathrm{N}$ and $\mathrm{T} \times \mathrm{I}$ interactions, explaining 7 and $1 \%$ of the variation in length, respectively). The presence of Fucus spp. germlings (C) did not significantly affect the length of E. compressa germlings at any temperature, nutrient or density treatment (Table 1). Increasing temperature had a strong positive effect on the length of $E$. compressa germlings, and this effect was most pronounced in the nutrient-enriched cultures at the low-density level (Fig. 3). Nutrient enrichment increased the mean length of $E$. compressa germlings by $\sim 20 \%$ at $7^{\circ} \mathrm{C}$, and by $\sim 150 \%$ at $17^{\circ} \mathrm{C}$.

\section{Yield and competition indices}

The monoculture yields of Fucus spp. and Enteromorpha compressa generally increased with settlement density (Fig. 4). E. compressa monoculture yields were always higher than those of Fucus spp. and this 

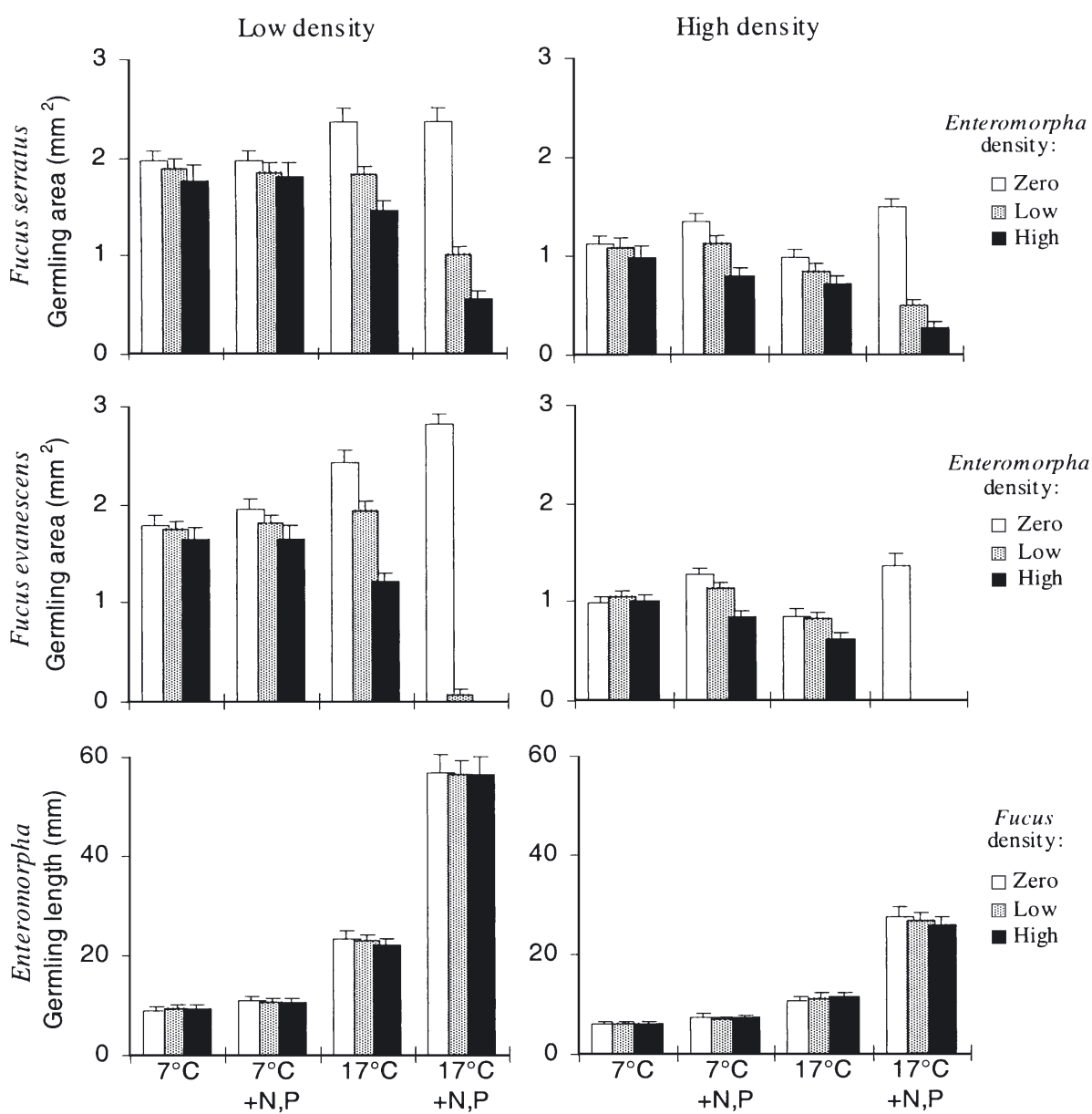

Fig. 3. Fucus serratus, F. evanescens and Enteromorpha compressa. Mean size of germlings at low and high settlement densities, in monocultures and mixtures after 1 mo treatment at 7 and $17^{\circ} \mathrm{C}$, in seawater and $\mathrm{N}+\mathrm{P}$ enriched seawater. Note different response variables for Fucus spp. (germling area) and E. compressa (germling length) graphs.

Further details as for Fig. 2

difference increased with increasing temperature and nutrient concentration. While the monoculture yield of Fucus never differed by more than 100\% between any combinations of temperature and nutrient concentration at any settlement density, E. compressa yield increased by $\sim 600 \%$ when temperature and nutrient levels were both increased. Fig. 4 shows the species monoculture and mixture yields (at the highest competitor density level) plotted against settlement density, along with the projections of 'competition-free' yield. The vertical distance between the 'competitionfree' yield projection and observed monoculture yield describes the absolute yield depression due to intraspecific competition, and the vertical distance between a species' monoculture and mixture yields measures the absolute yield depression due to interspecific competition. At the high settlement density, the vertical distance between the 'competition-free' yield projection and a species' mixture yield represents the total absolute yield depression due to competitive interactions, including both intra- and interspecific effects.

Intraspecific competition increased with increasing settlement density (Fig. 4), and the relative effects of intraspecific competition in the high-density monocultures of both Fucus species and Enteromorpha compressa increased significantly with increasing temperature and decreasing nutrient concentration (Fig. 5, 2 -way ANOVAs, p always < 0.05). In mixed cultures, the relative interspecific competition effects of E. Compressa on Fucus spp. germlings increased significantly with increasing temperature and nutrient levels (Fig. 5, 2 -way ANOVAs, p always < 0.05). In the nutrientenriched mixtures cultivated at $17^{\circ} \mathrm{C}$, interspecific competition from $E$. compressa reduced the yield of Fucus spp. by 80 to $100 \%$, with the yield of $F$. evanescens being significantly more reduced than that of $F$. serratus at all density combinations ( $t$-tests, $p$ always $<0.05)$. For the other temperature and nutrient combinations, the relative yield reductions of Fucus spp. caused by interspecific competition from E. compressa were always less than $70 \%$, and competition responses did not differ significantly between the 2 Fucus species at $7^{\circ} \mathrm{C}$ ( $t$-tests, p always $\left.>0.05\right)$. Neither of the Fucus species had any negative effect on the yield of E. compressa in mixtures at any temperature, nutrient and density combination (Figs. 4 \& 5). 


\section{Fucus serratus}
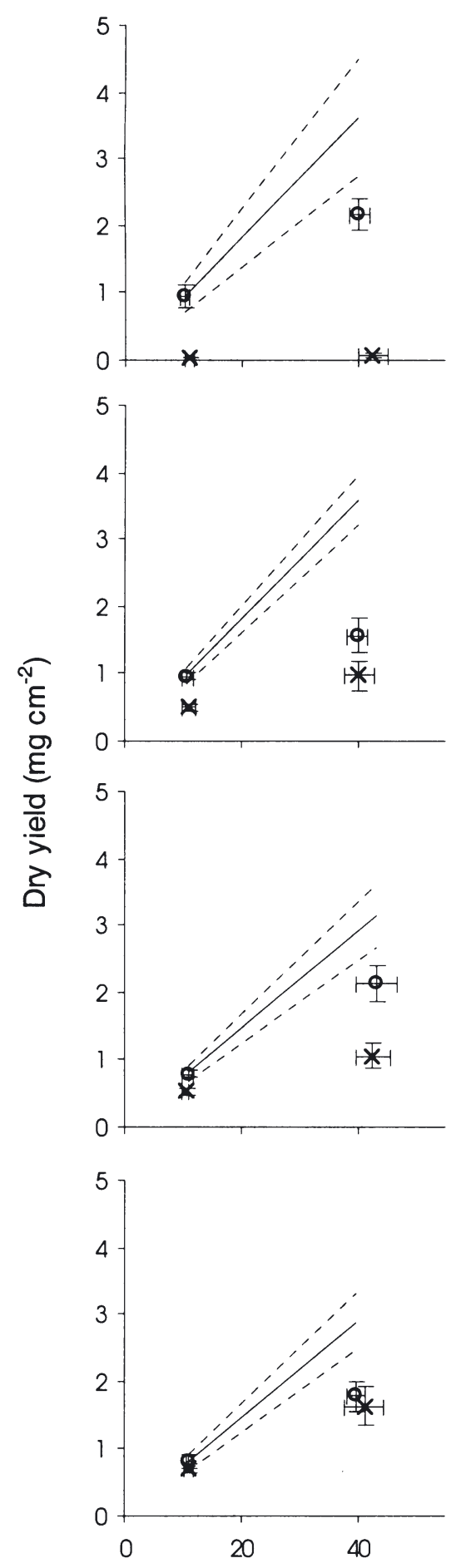

Fucus evanescens
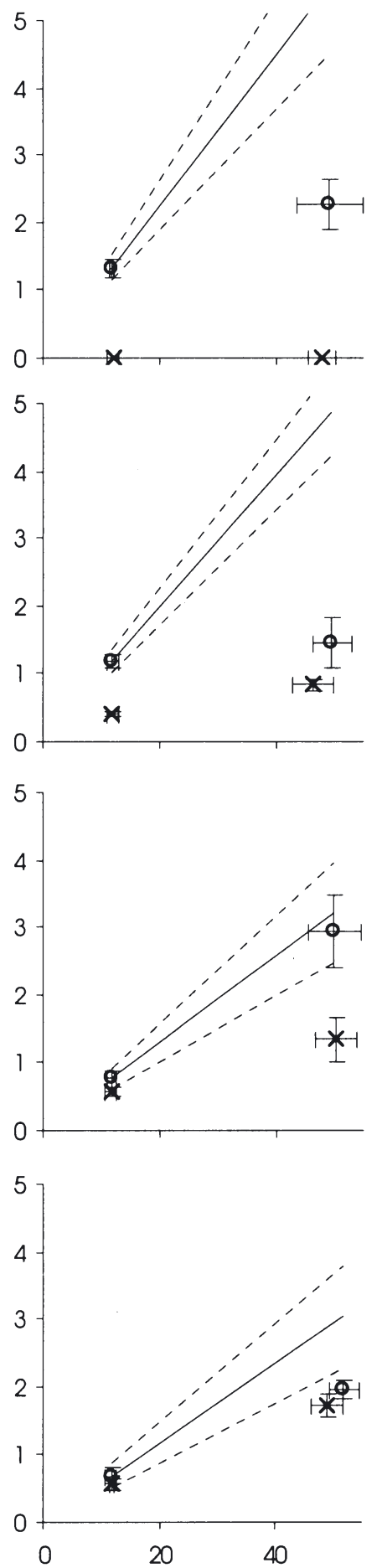

Enteromorpha
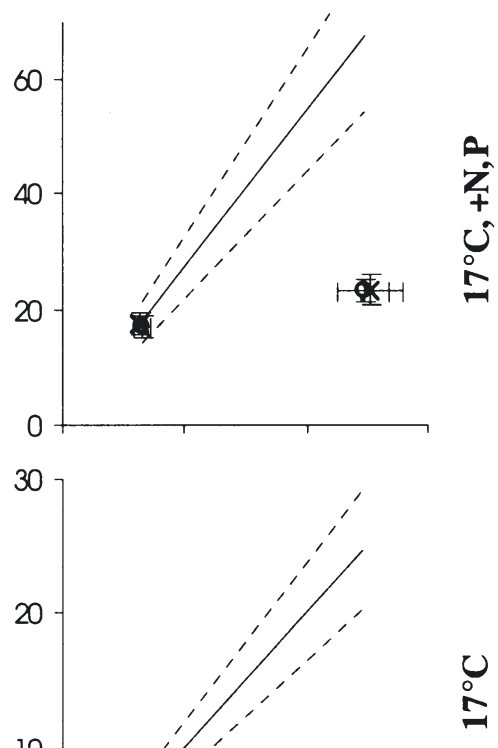

10
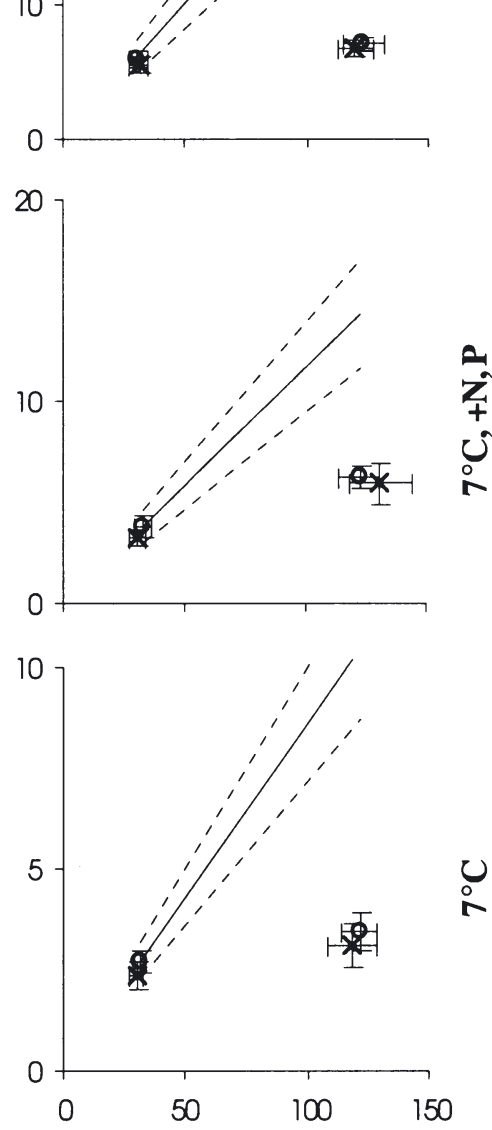

Settlement density (germlings $\mathrm{cm}^{-2}$ )

Fig. 4. Fucus serratus, F. evanescens and Enteromorpha compressa. Mean dry yield in monocultures (0) and high competitor density mixtures $(\mathbf{x})$ as a function of settlement density after 1 mo treatment at 7 and $17^{\circ} \mathrm{C}$ in seawater and $\mathrm{N}+\mathrm{P}$-enriched seawater. Linear diagonal projections represent estimated mean potential dry yield that would have been produced in a 'competition-free' environment (continuous lines) and its 95\% confidence limits (dashed lines). Note scale differences between graphs.

Further details as for Fig. 2 

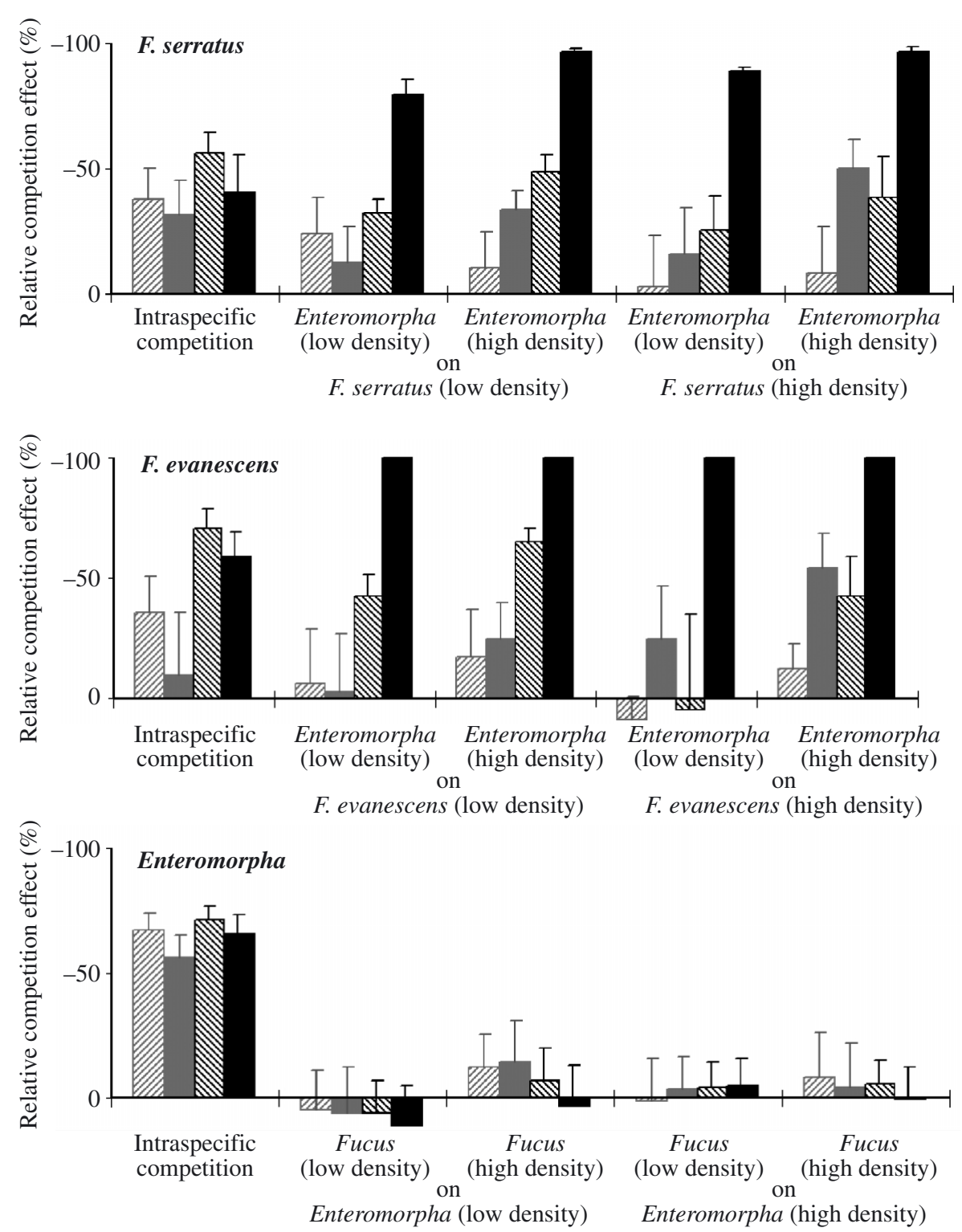

Fig. 5. Fucus serratus, F. evanescens and Enteromorpha compressa. Mean relative intraspecific and interspecific competition effects for various target species and competitor species density-combinations in cultures after 1 mo treatment in seawater (hatched bars) and $\mathrm{N}+\mathrm{P}$ enriched seawater (filled bars), at $7^{\circ} \mathrm{C}$ (grey bars) and $17^{\circ} \mathrm{C}$ (black bars). Relative competition effects were estimated as percentages on scale of 0 (no competition) to $-100 \%$ (competitive exclusion), whereas positive values indicate density facilitation. Further details as for Fig. 2

\section{DISCUSSION}

Nutrient enrichment of shallow coastal waters alters the composition of macroalgae communities so that fast-growing ephemeral algae replace slow-growing macrophytes such as fucoids. The decline of fucoids in eutrophic waters may be caused by direct negative effects of nutrient enrichment, and experiments have shown that survival and attachment ability of germlings in species like Ascophyllum nodosum (L.) Le Jolis and Fucus vesiculosus L. are negatively related to nutrient concentration (Choi 2001, Bergström et al. 2003). However, nutrient enrichment had no direct negative effect on either of the Fucus species tested in the present experiment, and the decline of F. serratus in eutrophic areas is probably caused by other factors.
Although fucoid algae could be negatively influenced by secondary factors often associated with eutrophication, such as toxic wastes (Wikström et al. 2000) and increased sedimentation (Chapman \& Fletcher 2002, Eriksson et al. 2002, Berger et al. 2003), their decline has commonly been attributed to competitive displacement by ephemeral algae. According to this hypothesis, ephemeral algae should benefit more from nutrient enrichment and/or be less negatively affected by other factors associated with eutrophication than the declining fucoids. The results of the present study support this hypothesis, as growth of Enteromorpha compressa germlings was significantly more stimulated by nutrient enrichment than growth of $F$. serratus and $F$. evanescens germlings. These results agree with observations indicating that ephemeral green algae have 
higher nutrient requirements for growth than Fucus species (Pedersen \& Borum 1996, 1997). Such responses do not necessarily correlate with algal morphology, as thin foliaceous forms like E. compressa, with a high surface/volume ratio, should be better equipped to derive nutrients from the water when availability is low than the coarser multilayered fucoids. However, compared to ephemeral algae, fucoid seaweeds have a better nutrient storage capability, with efficient internal nutrient recycling (Duarte 1995, Pedersen \& Borum 1996), and form hairs which increase the algae's surface area and nutrient uptake ability when availability is low (Steen 2003a).

Ephemeral algae may negatively affect fucoids through direct competitive interactions or by blocking the settlement of germlings (Berger et al. 2003). The early post-settlement period is probably a critical phase, as the minute fucoid germlings may easily become overgrown and outcompeted by fast-growing ephemeral algae. In the present experiments, growth and survival in germlings of Fucus serratus and F. evanescens were negatively affected by interspecific competition from Enteromorpha compressa, and the magnitude of this effect depended on nutrient concentration, temperature and settlement density. This is the first time that competitive interactions between $E$. compressa and these 2 Fucus species have been experimentally demonstrated, and the results show that nutrient enrichment, mediated by temperature, tilts the competitive relationship in favour of E. compressa as early as the germling stage. These results agree with those of Worm et al. (2001), who found that nutrient enrichment increased the negative effect of Enteromorpha spp. on $F$. vesiculosus germlings (but not adults) in field experiments in the Baltic Sea.

In the nutrient-enriched monocultures at $17^{\circ} \mathrm{C}$, Enteromorpha compressa accumulated 10 times more biomass than Fucus spp. after 1 mo of treatment (Fig. 4), and interspecific competition from E. compressa suppressed Fucus spp. germlings by 80 to $100 \%$ when the species were mixed together under these conditions (Fig. 5). In the nutrient-enriched monocultures kept at $7^{\circ} \mathrm{C}, E$. compressa accumulated 2 to 4 times more biomass than Fucus spp. and the suppressive effect of $E$. compressa on Fucus spp. germlings in mixtures never exceeded $60 \%$. This suggests that reproduction at low water temperatures $\left(7^{\circ} \mathrm{C}\right)$ may prove beneficial for fucoids in eutrophic areas by shielding the most vulnerable germling stages from the severest competition with ephemerals like E. compressa. Germlings of $F$. serratus and $F$. evanescens are produced early in the year, and have a high growth potential at $7^{\circ} \mathrm{C}(\sim 75 \%$ of that at $17^{\circ} \mathrm{C}$, Fig. 3), and may have reached a resistant stage before competition from ephemeral algae intensifies as the season progresses and the temperature rises. Despite being rapidly overgrown and competitively suppressed by ephemeral algae such as E. compressa during the early stages of substrate colonisation, fucoid germlings may persist and resume their growth when competition from the ephemeral alga becomes less intense as water temperature decreases in the autumn. Nevertheless, to succeed in the longterm, the fucoid germlings must at least survive the intense competition pressure from ephemeral algae during summer, and the chances of surviving this wave of ephemeral competition will probably depend on the developmental status of the germlings, which again depends on the timing of reproduction. Avoiding the hardest competition from ephemeral algae appears to be particularly important for young $F$. evanescens germlings, as few survived competition from E. compressa in the nutrient-enriched mixtures at $17^{\circ} \mathrm{C}$, which resembles summer temperatures in Norwegian shallow coastal waters (www.efan.no/Tempgraph).

While the distribution of Fucus serratus and several other fucoid species appears to be negatively related to eutrophication, observations indicate a positive relationship between eutrophication and the distribution of F. evanescens (Grenager 1957, Bokn \& Lein 1978, Bokn et al. 1992). If the success of $F$. evanescens in eutrophic waters depended solely on a favourable reproductive season to avoid competition from ephemeral algae, then $F$. serratus, whose reproduction starts earlier in the year and at lower water temperatures than that in F. evanescens (Steen \& Rueness 2004), should be facilitated too. There are several factors that might induce such interspecific differences in responses to eutrophication. A contributing factor could be that germlings of $F$. evanescens are less negatively affected by competition with ephemeral algae than F. serratus. However, the results obtained here did not support this, as the competition responses of the 2 Fucus species differed little when cultivated at $7^{\circ} \mathrm{C}$, and $F$. evanescens germlings were even more affected than $F$. serratus germlings by interspecific competition from $E$. compressa in the nutrient-enriched mixtures at $17^{\circ} \mathrm{C}$. In southern Scandinavia, F. evanescens is largely confined to harbour areas where abundance of other fucoids (e.g. Ascophyllum nodosum, F. vesiculosus, F. serratus) is low (Wikström et al. 2002), and where $F$. evanescens may have no competition from other fucoid species. As demonstrated here and in previous studies (Steen 2003a, Steen \& Scrosati 2004), the growth of $F$. evanescens germlings is more stimulated by nutrient enrichment than that of $F$. serratus germlings, and this may increase the competitiveness of $F$. evanescens in eutrophic areas.

Whereas Enteromorpha compressa exerted considerable competition pressure on Fucus spp. germlings, Fucus spp. did not affect the growth and survival of 
E. compressa germlings at any treatment combination. It may be argued that the use of a higher settlement density range for $E$. compressa in these experiments will give this species a competitive advantage. However, competition was also asymmetrical in the Fucus spp. (high-density)-E. compressa (low-density) mixtures where Fucus spp. germlings (40 to 50 germlings $\mathrm{cm}^{-2}$ ) initially outnumbered E. compressa germlings $\left(\sim 30\right.$ germlings $\left.\mathrm{cm}^{-2}\right)$. This asymmetrical competition relationship might be attributable to the different growth forms of these algae. Competitive dominance is generally believed to be positively correlated with plant size, since a larger plant creates a larger depletion zone for resources, especially light (Grime 1977 , Schmitt et al. 1986, Keddy et al. 2002, but see Olson \& Lubchenco 1990 and Worm \& Chapman 1998 for exceptions). After 1 mo of treatment, E. compressa germlings were from 4 times (unenriched monocultures at $7^{\circ} \mathrm{C}$ ) to $>15$ times (nutrient-enriched monocultures at $17^{\circ} \mathrm{C}$ ) longer than those of Fucus spp. germlings. Although my experimental design did not allow complete separation between light and nutrient competition, the frequent changes of growth medium probably ensured that competition for nutrients was low. The positive relationship between nutrient concentration and competition effects of E. compressa on Fucus spp. further indicates that interspecific competition was less intense for nutrients than for light. In the mixed-species cultures, nutrient enrichment, mediated by temperature, appeared merely to modify the interspecific competition for light by facilitating the growth of one species (E. Compressa) more than the other ( $F$. serratus or $F$. evanescens). As a result, shading effects were strongly 1-sided. E. compressa shaded Fucus spp. germlings increasingly with increasing temperature and nutrient concentration, whereas Fucus spp. germlings had minimal shading effects on E. compressa regardless of treatment. On the other hand, germlings appeared to compete more intensely for nutrients than light in monocultures, as nutrient enrichment decreased the intensity of intraspecific competition. Because they have similar growth forms, light competition will probably be more symmetrical among conspecifics than among contraspecifics as diverse as Fucus spp. and E. compressa.

On the shore, Enteromorpha compressa and Fucus species often settle in dense aggregates (Creed et al. 1996, Lotze 1998, Arrontes 2002), where germlings are likely to be affected by both intra- and interspecific competition. In the present experiments the magnitude of intra- and interspecific competition effects depended on the settlement density of germlings. In treatments where intra- and interspecific competition effects were comparable (high-density monocultures versus low target-species density mixtures), intraspe- cific competition had a stronger negative effect on Fucus spp. germlings than interspecific competition from E. compressa at the low nutrient level, whereas interspecific competition had more effect at the high nutrient level at $17^{\circ} \mathrm{C}$. For all 3 species examined here, intraspecific competition increased with increasing settlement density, probably because the resources available per individual were more limited at the higher densities. These results agree with previous findings for fucoid germlings (Creed et al. 1997, Choi 2001, Steen 2003b, Steen \& Scrosati 2004), and suggest that growth can be density-dependent during the early stages of substrate colonisation. As the germling densities used in the present experiments appear to be at the lower range of settlement densities observed for these species in the field (Creed et al. 1996, Lotze 1998), competition effects may be more devastating in field situations than the results obtained in this study suggest.

In monocultures, survival of Enteromorpha compressa germlings was always lower than that of Fucus spp. germlings, even in the cultures where settlement density of E. compressa was lower. This difference could be caused by a higher degree of self-shading and crowding-induced mortality among E. compressa germlings, as they accumulated more biomass than Fucus spp. at all treatment combinations (Fig. 4). Effects of density and biomass accumulation on the survival of algae germlings will probably depend on growing conditions. On the shore, members of densely populated algae associations may have better protection from physical stress and a higher chance of survival than more solitary individuals (Bertness \& Leonard 1997, Bertness et al. 1999, Choi 2001). Species of Enteromorpha and Fucus have different life-form strategies, and the high germling mortality of the ephemeral algae will probably be compensated for by a high reproductive output (Lotze 1998, Lotze et al. 1999, 2000, 2001).

The ecological relevance of results obtained from short-term laboratory experiments will always be difficult to predict for the larger spatial and temporal scales in the field, and ideally all ecological studies should be performed in situ. On the shore, a multitude of environmental variables (e.g. competition, grazing, resource supply, water chemistry, hydrodynamics, climatic conditions, physical disturbances) may affect macroalgae in patterns varying over several spatial and temporal scales (Åberg \& Pavia 1997, Menge 1997, Burrows \& Hawkins 1998). However, because of the complexity and variability of such systems it is difficult to identify the contributions of single mechanisms and estimate factorial interactions directly on the shore. Even in cases where it is possible to use natural gradients or manipulate factors on the shore, their contribu- 
tion may be obscured by the presence of unidentifiable and uncontrollable covariates, that may vary systematically in parallel with the investigated factors and mediate their effects. Forces operating in the microclimate inhabited by newly settled germlings will probably be particularly hard to identify and manipulate under inadequately controlled conditions. Moreover, some of the factors examined here (i.e. temperature and nutrient concentration) are extremely difficult to manipulate and control in the field without introducing other confounding elements. Laboratory experiments provide greater opportunities for both controlling and manipulating these factors independently and for estimating their effects on target organisms more precisely. The results obtained in the present study provide new information of the potential mechanisms behind the displacement of fucoids by ephemeral algae in eutrophic waters, and experimentally demonstrate that competition between these algae can be interactively modified by nutrient concentration, temperature and settlement density as early as the germling stage. Effects on germling performance and interactions will ultimately have consequences at higher levels of organisation in marine macroalgae communities.

Acknowledgements. I would like to thank the staff at the Marine Research Station of the Norwegian Institute for Water Research at Solbergstrand for providing seawater and nutrient supplies. Thanks are also due to Professor J. Rueness, Dr. S. Fredriksen, and Dr. T. Andersen for sharing their knowledge and experience with me. Finally I wish to thank 4 anonymous referees for reviewing and improving the quality of this paper.

\section{LITERATURE CITED}

Åberg P, Pavia H (1997) Temporal and multiple scale spatial variation in juvenile and adult abundance of the brown alga Ascophyllum nodosum. Mar Ecol Prog Ser 158: 111-119

Arrontes J (2002) Mechanisms of range expansion in the intertidal brown alga Fucus serratus in northern Spain. Mar Biol 141:1059-1067

Begon M, Harper JL, Townsend CR (1986) Ecology: individuals, populations and communities. Blackwell Scientific Publications, Oxford

Berger R, Henriksson E, Kautsky L, Malm T (2003) Effects of filamentous algae and deposited matter on the survival of Fucus vesiculosus L. germlings in the Baltic Sea. Aquat Ecol 37:1-11

Bergström L, Berger R, Kautsky L (2003) Negative direct effects of nutrient enrichment on the establishment of Fucus vesiculosus in the Baltic Sea. Eur J Phycol 38:41-46

Bertness MD, Leonard GH (1997) The role of positive interactions in communities: lessons from intertidal habitats. Ecology 78:1976-1989

Bertness MD, Leonard GH, Levine JM, Schmidt PR, Ingraham AO (1999) Testing the relative contribution of positive and negative interactions in rocky intertidal communities. Ecology 80:2711-2726

Bokn T, Lein TE (1978) Long-term changes in fucoid association of the inner Oslofjord, Norway. Norw J Bot 25:9-14

Bokn TL, Murray S, Moy FE, Magnusson JB (1992) Changes in fucoid distribution and abundance in the inner Oslofjord, Norway: 1974-80 versus 1988-90. Acta Phytogeogr Suec 78:117-124

Burrows MT, Hawkins SJ (1998) Modelling patch dynamics on rocky shores using deterministic cellular automata. Mar Ecol Prog Ser 167:1-13

Carpenter RC (1990) Competition among marine macroalgae -a physiological perspective. J Phycol 26:6-12

Chapman AS, Fletcher RL (2002) Differential effects of sediments on survival and growth of Fucus serratus embryos (Fucales, Phaeophyceae). J Phycol 38:894-903

Choi HG (2001) The effects of density on algal competition in culture and the field. PhD thesis, University of Liverpool

Connolly J (1986) On difficulties with replacement-series methodology in mixture experiments. J Appl Ecol 23: $125-137$

Cousens R (1996) Design and interpretation of interference studies: are some methods totally unacceptable? NZ J For Sci 26:5-18

Creed JC, Norton TA, Harding SP (1996) The development of size structure in a young Fucus serratus population. Eur J Phycol 31:203-209

Creed JC, Norton TA, Kain JM (1997) Intraspecific competition in Fucus serratus germlings: the interaction of light, nutrients and density. J Exp Mar Biol Ecol 212:211-223

Crowley PH (1992) Resampling methods for computationintensive data analysis in ecology and evolution. Annu Rev Ecol Syst 23:405-447

de Wit CT (1960) On competition. Versl Landbouwkd Onderz (Agric Res Rep) 66:1-82

Dixon PM (2001) The bootstrap and the jackknife: describing the precision of ecological indices. In: Scheiner SM, Gurevitch J (eds) Design and analysis of ecological experiments. Oxford University Press, New York, p 267-288

Donald CM (1958) The interaction of competition for light and for nutrients. Aust J Agric Res 9:421-432

Duarte C (1995) Submerged aquatic vegetation in relation to different nutrient regimes. Ophelia 41:87-112

Enright CT (1979) Competitive interaction between Chondrus crispus (Florideophyceae) and Ulva lactuca (Chlorophyceae) in Chondrus aquaculture. Proc Int Seaweed Symp 209-218

Eppley RW, Holmes RW, Strickland JDH (1967) Sinking rates of marine phytoplankton measured with fluorometer. J Exp Mar Biol Ecol 1:191-208

Eriksson BK, Johansson G, Snoeijs P (2002) Long-term changes in the macroalgal vegetation of the inner Gullmar Fjord, Swedish Skagerrak coast. J Phycol 38:284-296

Firbank LG, Watkinson AR (1985) On the analysis of competition within two-species mixtures of plants. J Appl Ecol 22: 503-518

Firbank LG, Watkinson AR (1990) On the effects of competiton: from monocultures to mixtures. In: Grace J, Tilman D (eds) Perspectives on plant competition. Academic Press, San Diego, p 165-192

Fletcher RL (1996) The occurrence of 'green tides' — a review. Ecol Stud 123:7-43

Grace JB (1995) On the measurement of plant competition intensity. Ecology 76:305-308

Grenager B (1957) Algological observations from the polluted area of the Oslofjord. Nytt Mag Bot 5:41-60

Grime JP (1977) Evidence for the existence of three primary 
strategies in plants and its relevance to ecological and evolutionary theory. Am Nat 111:1169-1194

Howell DC (1992) Statistical methods for psychology. Duxbury Press, Belmont

Hurlbert SH, Lombardi CM (2003) Design and analysis: uncertain intent, uncertain result. Ecology 84:810-812

Jolliffe PA, Minjas AN, Runeckles VC (1984) A reintepretation of yield relationships in replacement series experiments. J Appl Ecol 21:227-243

Karez R, Chapman AOR (1998) A competitive hierarchy model integrating roles of physiological competence and competitive ability does not provide a mechanistic explanation for the zonation of three intertidal Fucus species in Europe. Oikos 81:471-494

Keddy PA, Nielsen K, Weiher E, Lawson R (2002) Relative competitive performance of 63 species of terrestrial herbaceous plants. J Veg Sci 13:5-16

Kristiansen S, Paasche E (1982) Nitrogen nutrition of the phytoplankton in the Oslofjord. Estuar Coast Shelf Sci 14: 237-249

Law R, Watkinson AR (1987) Response-surface analysis on two-species competition: an experiment on Phleum arenarium and Vulpia fasciculata. J Ecol 75:871-886

Lotze HK (1998) Population dynamics and species interactions in macroalgal blooms, abiotic versus biotic control at different life-cycle stages. PhD thesis, Christian Albrecht Universität, Kiel

Lotze HK, Worm B (2002) Complex interactions of climatic and ecological controls on macroalgal recruitment. Limnol Oceanogr 47:1734-1741

Lotze HK, Schramm W, Schories D, Worm B (1999) Control of macroalgal blooms at early developmental stages: Pilayella littoralis versus Enteromorpha spp. Oecologia 119:46-54

Lotze HK, Worm B, Sommer U (2000) Propagule banks, herbivory and nutrient supply control population development and dominance patterns in macroalgal blooms. Oikos 89:46-58

Lotze HK, Worm B, Sommer U (2001) Strong bottom-up and top-down control of early life stages of macroalgae. Limnol Oceanogr 46:749-757

Markham JW, Hagmeier E (1982) Observations on the effects of germanium dioxide on the growth of macroalgae and diatoms. Phycologia 21:125-130

Menge BA (1997) Detection of direct versus indirect effects: were experiments long enough? Am Nat 149:801-823

Moran MD (2003) Arguments for rejecting the sequential Bonferroni in ecological studies. Oikos 100:403-405

Olson AM, Lubchenco J (1990) Competition in seaweeds: linking plant traits to competitive outcomes. J Phycol 26:1-6

Pedersen MF, Borum J (1996) Nutrient control of algal growth in estuarine waters. Nutrient limitation and the importance of nitrogen requirements and nitrogen storage

Editorial responsibility: Otto Kinne (Editor),

Oldendorf/Luhe, Germany among phytoplankton and species of macroalgae. Mar Ecol Prog Ser 142:261-272

Pedersen MF, Borum J (1997) Nutrient control of estuarine macroalgae: growth strategy and the balance between nitrogen requirements and uptake. Mar Ecol Prog Ser 161: 155-163

Quatrano RS (1980) Gamete release, fertilization, and embryogenesis in the Fucales. In: Gantt E (ed) Handbook of phycological methods: developmental and cytological methods. Cambridge University Press, Cambridge, UK, p 59-68

Russell G, Fielding AH (1974) The competitive properties of marine algae in culture. J Ecol 62:689-698

Schmitt J, Ehrhardt EW, Cheo M (1986) Light-dependent dominance and suppression in experimental radish populations. Ecology 67:1502-1507

Schoener TW (1983) Field experiments of interspecific competition. Am Nat 122:240-285

Simmons HG (1898) Algologiske notiser. II. Eininge algenfunde bei Drøbak. Bot Not 1898:117-123

Snaydon RW (1991) Replacement or additive designs for competition studies? J Appl Ecol 28:930-946

Steen H (2003a) Apical hair formation and growth of Fucus evanescens and F. serratus (Phaeophyceae) germlings under various nutrient and temperature regimes. Phycologia 42:26-30

Steen H (2003b) Intraspecific competition in Sargassum muticum (Phaeophyceae) germlings under various density, nutrient and temperature regimes. Bot Mar 46:36-43

Steen H, Rueness J (2004) Comparison of survival and growth in germlings of six fucoid species (Fucales, Phaeophyceae) at two different temperature and nutrient levels. Sarsia 89:175-183

Steen H, Scrosati R (2004) Intraspecific competition in Fucus serratus and F. evanescens (Phaeophyceae, Fucales) germlings: effects of settlement density, nutrient concentration, and temperature. Mar Biol 144:61-70

Tsuji K, Tsuji N (1998) Indices of reproductive skew depend on average reproductive success. Evol Ecol 12:141-152

Wikström S, Kautsky L, Malm T (2000) The effects of chlorinefree pulp mill effluents on reproduction and grazing interactions in Baltic Sea Fucus vesiculosus L. Ophelia 53: 173-179

Wikström SA, von Wachenfeldt T, Kautsky L (2002) Establishment of the exotic species Fucus evanescens C. Ag. (Phaeophyceae) in Öresund, southern Sweden. Bot Mar 45:510-517

Worm B, Chapman ARO (1998) Relative effects of elevated grazing pressure and competition from a red algal turf on two post-settlement stages of Fucus evanescens C. Ag. J Exp Mar Biol Ecol 220:247-268

Worm B, Lotze HK, Sommer U (2001) Algal propagule banks modify competition, consumer and resource control on Baltic rocky shores. Oecologia 128:281-293

Submitted: November 7, 2003; Accepted: May 6, 2004

Proofs received from author(s): August 18, 2004 